\title{
NADIR - Núcleo de Antropologia do Direito
}

O Núcleo de Antropologia do Direito foi "apelidado" NADIR tanto em razão das letras iniciais de seu "nome completo" quanto (e principalmente!) em função de alguns significados da palavra que, por exemplo, em astronomia, designa o ponto inferior da esfera celeste, a projeção do alinhamento vertical que está sob os pés de um observador ou, ainda, o oposto ao zênite. Já em hebraico e em árabe nadir significa "raro". Enfim, como nomear é criar, tratamos de pensar nosso grupo como um lugar náo óbvio (embaixo, oposto) e, talvez, por isto mesmo, precioso para se pensar as múltiplas interfaces existentes e possíveis entre antropologia e direito.

"Nós", que agora somos 23 pesquisadores, no início de 2008 não chegávamos a 10, dentre os quais sempre estiveram presentes os orientandos da coordenadora, Profa. Ana Lúcia Pastore Schritzmeyer, uma vez que consideramos a participação nas reunióes e demais atividades do NADIR momentos especiais de troca, de enriquecimento e de descoberta de potencialidades e limitaçóes de nossos próprios trabalhos à luz dos trabalhos dos colegas.

Durante o ano de 2008 realizamos 18 reuniôes, geralmente no espaço da Sala do Conselho do Departamento de Antropologia. Nossos desafios, no primeiro semestre daquele ano, foram selecionar, estudar e discutir alguns textos considerados clássicos na área da antropologia do direito ou antropologia jurídica, como o debate travado entre Paul Bohannan e Max Gluckman sobre os problemas relativos à utilização de categorias do direito ocidental moderno - obrigação, dívida e contrato, por exemplo - para a compreensáo de relaçóes praticadas em contextos "nativos" particulares ${ }^{1}$. Vários outros textos de autores como Malinowski e Mauss também foram debatidos e, apesar de muitos terem sido listados para as reunióes do segundo semestre, decidimos que elas seriam dedicadas à apresentação de produçóes de membros do grupo, tais como papers preparados para congressos, projetos de pesquisa, relatórios de qualificação, artigos e dissertaçóes de mestrado.

Em 2009 já éramos mais de quinze e, novamente, realizamos 18 reunióes de estudo. Animados com o sucesso das leituras e debates do ano anterior, demos prosseguimento, no primeiro semestre, à retomada de "clássicos", especialmente Durkheim e Weber. A novidade foi que, simultaneamente, abrimos espaço para alguns professores-pesquisadores de outras universidades exporem suas trajetórias de pesquisa e, graças a muitas reuniōes extraordinárias, também planejamos e organizamos o I ENADIR - Encontro Nacional de Antropologia do Direito - que ocorreu entre os dias 21 e 22 de agosto ${ }^{2}$. Para nossa alegria e gratificação, mais de 100 pessoas, das mais variadas regióes do país e de diferentes níveis e áreas de formação acadêmica, acompanharam as mesas redondas e participaram dos grupos de trabalho, demonstrando que, realmente, existe no Brasil um campo que responde pelo título de antropologia do direito. Esse intenso ano de 2009 foi coroado com a conclusão da primeira pesquisa coletiva realizada pelo NADIR: Direitos Humanos - Percepçóes dos alunos da Escola Estadual Antonio Adib Chammas (Santo Andrél SP, 2009), a qual contou com os apoios de duas Pró-Reitorias da USP (a de Pesquisa e a de Cultura e Extensão Universitária), do Depto de Antropologia e da ANDHEP - Associação Nacional de Direitos Humanos, Pesquisa e Pós-Graduaçáo.

Neste ano de 2010, já realizamos 17 reuniôes e mais 3 estão previstas até o início de 
370 | NADIR - Núcleo de Antropologia do Direito

dezembro. Os membros do NADIR seguiram expondo o andamento de seus trabalhos, acompanhando bancas dos colegas que chegaram à qualificação ou defesa e alguns professores convidados nos apresentaram novas perspectivas interdisciplinares para a já interdisciplinar antropologia do direito. Este também foi um tempo de investimentos em trocas mais efetivas com grupos internacionais similares, especialmente o Laboratoire de la Chaire de Recherche $d u$ Canada (CRC) en Traditions Juridiques et Rationalité Pénale e o Centre Interdisciplinaire de Recherche sur la Citoyenneté et les Minorités (CIRCEM), ambos da Faculté des Sciences Sociales de l'Université d'Ottawa/ Canadá. Em Paris, nosso principal contato é com o LAJP - Laboratoire d'Anthropologie Juridique de Paris, da Université Paris 1 - Panthéon-Sorbonne, cuja diretora, Gilda Nicolau, está convidada para nos visitar no primeiro semestre de 2011.

Para o ano que vem, portanto, além de incrementarmos esses contatos internacionais e estabelecermos outros, inclusive porque alguns membros do NADIR já estão fazendo ou farão intercâmbios no exterior, nossa principal meta é a realização do II ENADIR, em agosto, nos moldes do primeiro, porém com mais GTs e novas temáticas para as mesas redondas, para o que contatos preliminares e projetos já estáo em andamento. Também pretendemos reeditar a pesquisa finalizada em 2009, porém em outra escola pública estadual, e já contamos novamente com os apoios da Pró-Reitoria de Pesquisa da USP e da ANDHEP.

Por fim, faz-se urgente repensarmos nosso espaço no site do Departamento de Antropologia, nele disponibilizando mais informaçóes sobre nossas atividades passadas, presentes e futuras, individuais e coletivas, de modo a que os interessados pelos caminhos e descaminhos da antropologia do direito, estejam eles no Brasil e no exterior, possam nos conhecer e se aproximar, com mais facilidade e mais subsídios para conosco estabelecer diálogos e projetos.

A equipe de pesquisadores do NADIR conta, atualmente, com o seguinte perfil de colaboradores:

\begin{tabular}{|l|l|l|l|l|l|l|}
\hline \multirow{2}{*}{$(30 / 09 / 2010)$} & Formação (maior titulação) & \multicolumn{3}{l|}{ Vínculo atual com } & Totais \\
\cline { 2 - 8 } & Direito & CSO/Antropologia & Outra & aUSP & Outras instituições & \\
\hline Graduandos & 4 & 3 & & 7 & & 7 \\
\hline Graduados & 3 & & 1 & & 4 & 4 \\
\hline Mestrandos & & 7 & & 7 & & 7 \\
\hline Mestres & & 2 & & & 2 & 2 \\
\hline Doutorandos & 1 & 1 & & 2 & & 2 \\
\hline Doutores & & 1 & & 1 & & 1 \\
\hline Totais & 8 & 14 & 1 & 17 & 6 & 23 \\
\hline
\end{tabular}

E esse "número 23" é constituído pela alegria, presença, companheirismo, questôes, idéias, disposição para trabalhar e otimismo das seguintes pessoas:

\begin{tabular}{|l|l|}
\hline Pesquisadores(as) & Formação \\
\hline Adalton José Marques (afastado) & Graduando em Filosofia, Graduado em CS0 e Mestre em Antropologia \\
\hline Adriana Rezende Faria Taets & Graduada em CS0 e Mestranda em Antropologia \\
\hline $\begin{array}{l}\text { Ana Gabriela Mendes Braga (com bolsa sanduíche no exterior - } \\
\text { Espanha) }\end{array}$ & Graduada em Direito, Mestre e Doutoranda em Direito Penal e Criminologia \\
\hline Ana Letícia de Fiori & Graduada em CSO e Mestranda em Antropologia \\
\hline
\end{tabular}


NADIR - Núcleo de ANTropologia do Direito | 37 I

\begin{tabular}{|l|l|}
\hline Bruna Soares Angotti Batista de Andrade & Graduada em CSO e em Direito, Mestranda em Antropologia \\
\hline Carmen Sílvia Fullin (com bolsa sanduíche no exterior - Canadá) & $\begin{array}{l}\text { Graduada em CSO e em Direito, Mestre em Sociologia e Doutoranda em } \\
\text { Antropologia }\end{array}$ \\
\hline Diana Paola Gómez Mateus & Graduada e Mestranda em Antropologia \\
\hline Erika Giuliane Andrade Souza & Graduada em Direito e Mestre em Antropologia \\
\hline Fábio Ozias Zuker (fará intercâmbio na França, em 2011) & Graduando em CSO \\
\hline Filipe Gonçalves de Souza Nogueira da Silva (em intercâmbio no \\
exterior - Itália) & Graduanda em CSO \\
\hline Heloísa Helena de Farias Rosa & \\
\hline Igor Rolemberg Gois Machado & Graduanda em Filosofia, Graduada em Direito e Advogada \\
\hline Ilana Casoy & Graduando em Direito \\
\hline Jéssica Maria Benedetti & Especialista em Criminologia \\
\hline Laura Sarti Cortês & Graduanda em Direito \\
\hline Maíra Cardoso Zapater & Graduanda em Direito \\
\hline Paulo Leonardo Martins (afastado) & Graduanda em CSO e Graduada em Direito \\
\hline Raphael Paulino Gimenes & Graduado em Direito \\
\hline Raphael Tadeu Sabaini & Graduando em CSO \\
\hline Rebeca Campos Ferreira & Graduado em CSO e Mestrando em Antropologia \\
\hline Tatiana Santos Perrone & Graduada em CSO e Mestranda em Antropologia \\
\hline Thais Diniz Coelho Souza (em intercâmbio no exterior - França) & Graduada em CS0 e Mestranda em Antropologia \\
\hline Ana Lúcia Pastore Schritzmeyer \\
(coord.) & Graduanda em Direito \\
\hline
\end{tabular}

\section{Notas}

1. GLUCKMAN, Max. Obrigação e dádiva; BOHANNAN, Paul V. Etnografia e Comparação em Antropologia do Direito. In: DAVIS, Shelton H. (Org.). Antropologia do direito. Rio de Janeiro: Zahar Editores, 1973, p. 25-56 e 101-123.

2. Toda a programação do encontro, a maioria dos 60 papers aceitos para apresentação oral nos 6 GTs e os resumos das 10 palestras proferidas nas mesas redondas encontram-se disponíveis em: http://www.fflch. usp.br/da/arquivos/i_enadir_2009/

cadernos de campo, São Paulo, n. 19, p. 369-371, 2010 